\title{
3D Model - Furnish the GreySpace
}

\author{
Aanchal V. Dubey \\ Computer Engineering \\ Department, \\ Shah \& Anchor Kutchhi \\ Engineering College, \\ Mumbai, India
}

\author{
Manav R. Shah \\ Computer Engineering \\ Department, \\ Shah \& Anchor Kutchhi \\ Engineering College, \\ Mumbai, India
}

\author{
Shweta J. Solanki \\ Computer Engineering \\ Department, \\ Shah \& Anchor Kutchhi \\ Engineering College, \\ Mumbai, India
}

\author{
Mrs. Vaishali Kosamkar, \\ Assistant Professor \\ Computer Engineering \\ Department, \\ Shah \& Anchor Kutchhi \\ Engineering College, \\ Mumbai, India
}

\begin{abstract}
E-commerce is booming at a breakneck pace in this internet age. People in the industrialized world, as well as an increasing number of people in the developing world, now make daily purchases through e-commerce websites. Even Nevertheless, the spread of e-commerce in the developing world is still limited, and there is much to be desired. Ecommerce combined with the Augmented Reality is a boom to the growing technology. This paper, discusses the various facets of establishing an e-commerce website along with the Augmented Reality by giving the customers/users a realistic experience of the products they intend to buy. The database architecture is also examined, with a focus on relational connectivity. This approach to building an e-commerce website with the Augmented Reality can be simply copied and followed in establishing e-commerce websites in emerging and underdeveloped countries where resources are limited and expensive due to socio-economic factors. This paper presents the design and implementation of an e-commerce system based on React and AR to make online purchasing more convenient. It primarily covers the online shopping program, online payment, order generation, and product viewing in AR.
\end{abstract}

Keywords - E-commerce, Augmented Reality, 3D, database architecture

\section{INTRODUCTION}

The buying and selling of things or services through the internet is known as eCommerce, often known as electronic commerce or internet commerce. It entirely operates over the internet. We have developed a B2C (Business to customer) e-commerce website with an additional feature of Augmented Reality (AR). Augmented reality combines the real world with a computer-generated or virtual environment. It is accomplished by superimposing computer-generated pictures over real-world photos. It has a wide range of real-world applications. Medical, education, manufacturing, robotics, and entertainment are just a few of the industries where augmented reality is applied.

This website consists of both back-office and storefront. Only the admin will have access to the back-office where he has privileges of manipulating the categories and products, viewing the orders, shipping orders, etc. The customers have the access to the store-front where they can view various products of different categories along with their details. They can also view these products in $A R$ and then purchase it.

\section{FEATURES}

This website provides various functionalities such as only authorized users who have already registered can access the website, the products can be viewed in AR for users to get a realistic experience, both on Android as well as IOS. Various other functionalities such as add, delete or modify the products and category for admin.

Payment gateway feature for making online payment for the customers for buying the product. Shipment confirmation email will be sent to the customers once the admin gives shipment order. There is also a feature of sharable link or scannable QR code. Above all it's a userfriendly website which can be used by any end users.

\section{HOW IT WORKS}

A. Admin side:

We will see the admin side where he will have to login first, if the user is using the website for the first time he will have to register first and then login. Once logged in the admin will have three options either he can add or manage the products and category or see the shipment details.

For checking the shipment details which is basically details related to the orders placed by the customers, if the product is not shipped he can select ship now option.



Figure 1: Admin side 


\section{MODULES}

B. Customer side:

Like admin the customer will also have to login in order to view or buy any products. If the customer is not yet registered to the portal/website he/she will have to register first. After logging in the customer will be directed to a landing page from where he/she can navigate to other parts of the website. The customers can see the products in $3 \mathrm{D}$ on the web as well as in the AR.

The customer can also share a particular product using a sharable link or scanning a QR code for the same. Customer will also have the filter option to view the products in a particular manner. The customer can add the product to wishlist or to cart in order to buy it. Further the customer will be directed for billing where they can purchase it through payment gateway. Order details section has all the details of the order of a particular customer. The customers will also receive a notification when there product is shipped.

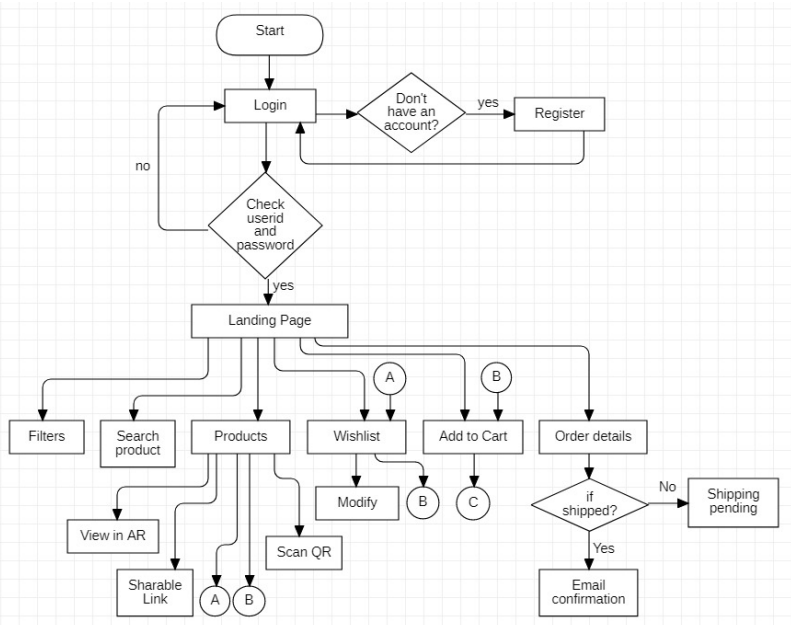

Figure 2.1: Customer side(A)

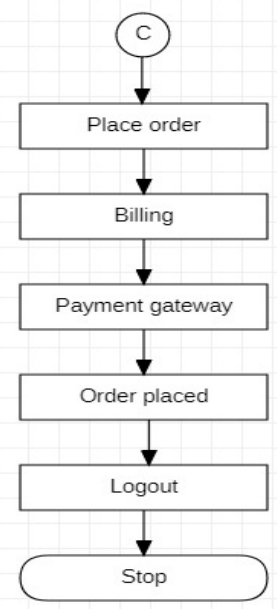

Figure 2.1:Ciustomer side(B)

\section{A. Admin side}

- Signin / Signup: The admin will have to login first in order to use the functionalities.

- Category add / delete: Here the admin can add or even delete various categories which is to be displayed on the website.

- $\quad$ Product add / delete: Here the admin can add or even delete the products which is to be sold on the website.

- Category modification: Here admin can update or make changes in any category details.

- Product modification: Here admin can update any product details.

- Shipment Details: The owner can view all the details related to the customer, product and whether the product is shipped or not, if not then the owner can give a command to ship the product.

\section{B. Customer side}

- Product display: Displaying all the products on the website.

- AR facility: The user can view the product in AR on android as well as on IOS devices.

- Filters: User can view the products as per their requirements.

- Search product: The user can search a particular product here.

- Add to Cart: Users can add required products in the cart.

- Wishlist option: User can add products in the wishlist.

- Billing: Once the user clicks on place order, a bill of total amount will be generated with the discount.

- Payment Gateway: User can pay for the product using the payment gateway.

- Order details: All the details of the order will be displayed to the user.

- Email facility: A confirmation mail will be sent to the user regarding the order placed and shipment. 


\section{IMPLEMENTATION}

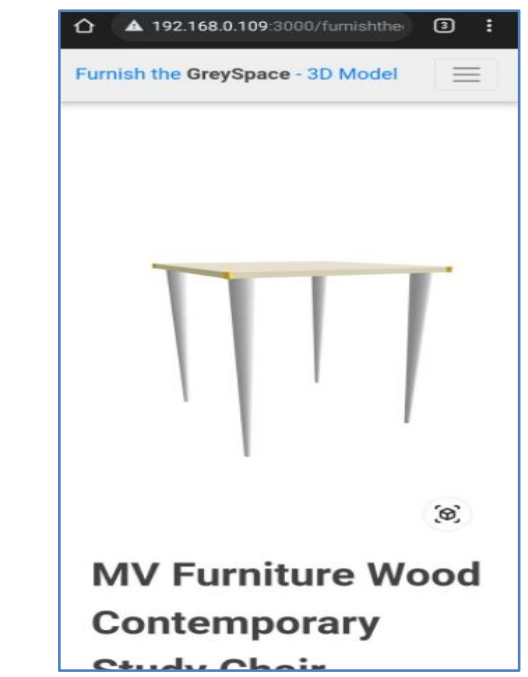

Figure 3.1:Product displayed in mobile view

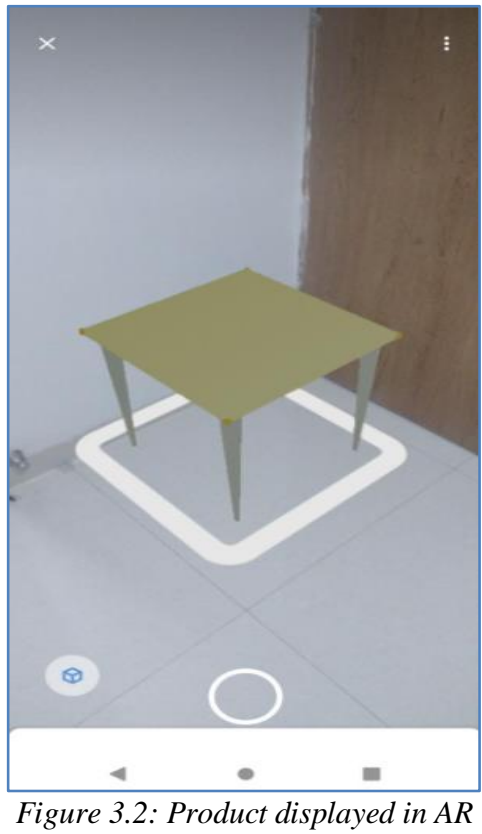

\section{CONCLUSION}

Thus "3D Model - Furnish the GreySpace" is an ecommerce website which not only provides the customers with a platform to buy products but also helps him to view the products in AR for both Android and IOS users which will give them a realistic experience of the product. It also helps the admin to manage his products and orders efficiently and with ease.

There can be made many changes to make it more advanced in future like multiple sellers can sell their products or various others products along with groceries, clothing etc can be included. User can also track his order and feature of coupons can also be included.

\section{REFERENCES}

[1] Zhang Changhao, Li Hu, Chen Xiangang, Shi Xiaolei, 'Research on Web 3D display based on STL model', IEEE, 2020.

[2] Rail Kadyrov, 'Developing of USDZ models for 3D digital analysis results visualization in augmented reality', Scientific Visualisation, 2020.

[3] Babak Sanii, 'Creating Augmented Reality USDZ Files to Visualize 3D Objects on Student Phones in the Classroom', Chemical Education, 2019.

[4] Sameer Saxena, Sonali Vyas, B. Suresh Kumar, Shaurya Gupta, 'Survey on Online Electronic Payments Security', IEEE, 2019.

[5] Anny Yuniarti, Ardian Atminanto, Anggi Mardasatria, Ridho Rahman Hariadi, Nanik Suciati, '3D ITS Campus on the Web: A WebGL Implementation', ICTS, 2015.

[6] Jibong Liu, Zhenjie Zhao, 'A study on 3D model based knowledge', IEEE, 2014.

[7] GAO Lan-juan, LIU Quan, JIANG Xue-mei, 'The Design and Implementation of the Online Shopping System for Digital Arts', IEEE, 2010.

[8] Emb3D 3D Model Viewer - App for viewing 3D models.

[9] https://www.lenskart.com/

[10] http://www.greentoken.de/onlineconv/

[11] https://products.aspose.app/3d/conversion/obj-to-gltf 